\title{
Proinflammatory and anti-inflammatory cytokines in meningococcal disease
}

\author{
F Andrew I Riordan, Omnia Marzouk, Alistair PJ Thomson, John A Sills, C Anthony Hart
}

\begin{abstract}
Interleukin-10 (IL-10), an anti-inflammatory cytokine, was measured in 131 children with meningococcal disease. IL-10 concentrations were significantly higher in children who died and correlated positively with proinflammatory cytokines. Children who die from meningococcal disease have high IL-10 concentrations, which do not suppress proinflammatory cytokines.

(Arch Dis Child 1996;75:453-454)
\end{abstract}

Keywords: meningococcal infection, interleukin-10, septic shock.

Mortality from meningococcal disease remains high, especially in meningococcal septic shock. The central mediator of septic shock is the proinflammatory cytokine, tumour necrosis factor- $\alpha$ (TNF- $\alpha)$. High concentrations of TNF- $\alpha$ are associated with death in meningococcal disease. ${ }^{1}$ Interleukin-10 (IL-10) is an anti-inflammatory cytokine that can inhibit the production of TNF- $\alpha$ in vitro. ${ }^{2}$ IL-10 may thus influence the progression of septic shock. Three small studies have found high concentrations of IL-10 in meningococcal septic shock. ${ }^{3-5}$ However in only one study were high concentrations associated with death. ${ }^{5}$

This study sought to measure concentrations of IL-10 in a large cohort of children with meningococcal disease, and to compare them with concentrations of proinflammatory cytokines (TNF- $\alpha$, IL-6).

Institute of Child

Health and

Department of

Medical Microbiology,

University of Liverpool

F A I Riordan

O Marzouk

Institute of Child

Health, University of

Liverpool

A P J Thomson

J A Sills

\section{Department of}

Medical Microbiology,

University of Liverpool

C A Hart

Correspondence and reprint requests to: Dr F A I Riordan, Undergraduate

Teaching Centre,

Birmingham Heartlands

Hospital, Bordeseley Green

East, Birmingham B9 5SS.

Accepted 14 August 1996

\section{Methods}

DEFINITIONS

Meningococcal disease was defined using the Meningococcal Disease Surveillance Group criteria. ${ }^{6}$ Septic shock was defined when systolic blood pressure was less than the 5 th centile for age.

\section{PATIENTS}

Children were included from two prospective studies of meningococcal disease on Merseyside from November 1988 until August 1990, and from September 1992 until April 1994. Consecutive children with meningococcal disease at the Royal Liverpool Children's Hospitals (Alder Hey and Myrtle Street), and Arrowe Park, Whiston, Warrington, and the Countess of Chester hospitals were enrolled. Alder Hey also received tertiary referrals to the regional paediatric intensive care unit (PICU) from other hospitals. The study was approved by the local research ethics committee of each hospital.

\section{CYTOKINE ASSAY METHODS}

Blood for cytokine measurement was taken on admission to hospital. The sample was kept on ice until separated within one hour of collection and stored at $-70^{\circ} \mathrm{C}$. Cytokine concentrations were measured in batches using an immunoenzymatic assay (Medgenix Diagnostics, Brussels). Lower limits of detection of the assays for $T N F-\alpha, \mathrm{IL}-6$, and IL-10 were 3 $\mathrm{pg} / \mathrm{ml}, 10 \mathrm{pg} / \mathrm{ml}$, and $1 \mathrm{pg} / \mathrm{ml}$ respectively.

STATISTICAL ANALYSIS

Statistical analysis was performed using SPSS/ PC+ version 5. For non-parametric continuous data the Mann-Whitney U test and Spearman's rank correlation coefficient were used. A $p$ value below 0.05 was considered significant.

\section{Results}

Two hundred and seventy eight children with meningococcal disease were seen during the two studies (152 in the first, 126 in the second); 26 (9.4\%) died. Samples for cytokine measurements were collected from 131 of these children (mostly those on the PICU), 19 (14.5\%) of whom died. The median age (range) was 22 months (2-179). Positive cultures or antigen for Neisseria meningitidis were found in $94(72 \%)$.

IL-10 concentrations were significantly higher in those who died compared with survivors (table 1); values were also significantly higher in septic shock (see table 1). IL-10 concentrations correlated strongly with TNF- $\alpha$ $(r=0.66 ; \mathrm{p}=0.0001)$ and IL-6 $(r=0.59$; $\mathrm{p}=0.0001)$. TNF- $\alpha$ and IL-6 were also significantly raised in those who died, as well as in septic shock (table 1).

\section{Discussion}

In this study concentrations of IL-10, a cytokine synthesis inhibitor, correlated positively with concentrations of two proinflammatory cytokines known to be associated with septic shock and death, TNF- $\alpha$ and IL-6. IL-10 was also significantly associated with septic shock and death.

Raised values of IL-10 have previously been found in patients with meningococcal septic shock. ${ }^{3-5}$ The current study is the largest study of IL-10 in meningococcal disease, comprising more subjects than the previous three studies combined. High IL-10 concentrations were associated with disease severity but not with mortality in two of these studies, probably 
Table 1 Cytokine concentrations ( $p g / m l)$ on admission in children with meningococcal disease; data shown as median (range)

\begin{tabular}{|c|c|c|}
\hline$\cdot$ & & $p$ Value ${ }^{*}$ \\
\hline \multicolumn{3}{|l|}{ IL-10 (pg/ml) } \\
\hline Died $(n=19)$ & Survived $(n=112)$ & \\
\hline $1565(6.3-3000)$ & $12(<1-3162)$ & 0.00001 \\
\hline Septic shock $(n=52)$ & Not shocked $(n=79)$ & \\
\hline $1446(<1-3000)$ & $1(<1-3162)$ & 0.00001 \\
\hline \multicolumn{3}{|l|}{ TNF- $\alpha(\mathrm{pg} / \mathrm{ml})$} \\
\hline Died $(n=17)$ & Survived $(n=105)$ & \\
\hline $1437(72-2291)$ & $74(3-1603)$ & 0.00001 \\
\hline Septic shock $(n=46)$ & Not shocked $(n=76)$ & \\
\hline $487(18-2291)$ & $54(3-1501)$ & 0.00001 \\
\hline \multicolumn{3}{|l|}{$\mathrm{IL}-6 \dagger(\mathrm{pg} / \mathrm{ml})$} \\
\hline Died $(n=18)$ & Survived $(n=106)$ & \\
\hline$>2000(885->2000)$ & $1545(<10->2000)$ & 0.00001 \\
\hline Septic shock $(n=49)$ & Not shocked $(n=75)$ & \\
\hline$>2000(49->2000)$ & $1171(<10->2000)$ & 0.00001 \\
\hline
\end{tabular}

* Difference by Mann-Whitney U test.

† Upper limit of assay for IL-6 $=2000 \mathrm{pg} / \mathrm{ml}$

related to the small numbers studied. The current study confirms significantly higher IL-10 concentrations in those who die. ${ }^{5}$

This study also confirms that high values of TNF- $\alpha$ and IL- 6 are associated with death in meningococcal disease and that TNF- $\alpha$ and IL-6 correlate strongly with each other. ${ }^{14}$

\section{Key messages}

- High concentrations of proinflammatory cytokines are associated with death from meningococcal septic shock

- IL-10, an anti-inflammatory cytokine, decreases synthesis of proinflammatory cytokines in vitro and could be a novel treatment for sepsis

- High concentrations of IL-10 were already present on admission in children who died from meningococcal disease

- The administration of IL-10 in meningococcal septic shock is unlikely to be beneficial

INTERACTION OF IL-10 AND TNF- $\alpha$

Raised IL-10 concentrations were only found when TNF- $\alpha$ was also raised. These findings suggests that TNF- $\alpha$ and IL-10 share a common stimulus, most probably endotoxin, and that IL-10 is rapidly released with TNF- $\alpha$. These data are not concordant with in vitro data suggesting IL-10 is released some time after TNF- $\alpha$. $^{2}$ In vitro studies of cytokines should thus be applied with caution in clinical settings. Only admission cytokine concentrations were measured in this study. Serial values may provide more information on the interactions between TNF- $\alpha$ and IL-10.

IL-10 has been suggested as a candidate for treatment of sepsis as it decreases proinflammatory cytokine production and increases their inhibitors. The current study suggests that enough TNF- $\alpha$ may already have been secreted before admission for any subsequent inhibition with IL-10 to be of little benefit. Further studies of the increasingly complex interactions between cytokines in meningococcal disease are required. Anticytokine treatment will need to find the balance between inhibiting harmful excessive host responses and abolishing essential defences and natural protective mechanisms. The administration of IL-10 to children with severe meningococcal disease is unlikely to be beneficial.

We would like to thank our paediatric colleagues for allowing us to study their patients, Nigel Hood and Steve Holland for the cytokine measurements and the National Meningitis Trust, the Johanne Holly Trust, and Centocor BV for financial support.

1 Waage A, Brandtzaeg P, Halstensen A, Kierulf P, Espevik T Waage A, Brandtzaeg $P$, Halstensen $A$, Kerum from patients The complex pattern of cytokines in serum from patients with meningococc

2 de Waal Malefyt R, Abrams J, Bennet B, Figdor C, de Vries J. Interleukin 10 (IL-10) inhibits cytokine synthesis by human monocytes: an auto-regulatory role of IL-10 produced by monocytes. $\mathcal{F}$ Exp Med 1991;174:1209-20.

3 Derkx B, Marchant A, Goldman M, Bijlmer R, van Deventer $S$. High levels of interleukin-10 during the initial phase of fulminant meningococcal septic shock. $f$ Infect $D$ is 1995;171:229-32.

4 van Deuren $M$, van der Ven-Jongerkrijg, Bartelink AKM van Dalen R, Sauerwein RW, van der Meer JWM. Correlavan Dalen R, Sauerwein RW, van der Meer JWM. Correlation between proinflammatory cytokines and antinflamcoccal infections. F Infect Dis 1995;172:433-9.

5 Lehmann AK, Halstensen A, Sørnes S, Røkke O, Waage A. High levels of interleukin-10 in serum are associated with fatality in meingococcal disease. Infect Immun 1995;63: 2109-12.

6 Meningococcal Disease Surveillance Group. Meningococcal disease: secondary attack rate and chemoprophylaxis in the United States, 1974. $₹ A M A$ 1976;235:261-5. 